\title{
Objective and Subjective Dental Treatment Needs among Nursing Home Residents
}

\author{
Carolin Mäding1* ${ }^{*}$ Jörg Klewer ${ }^{1}$, Robby Dietrich ${ }^{2}$ \\ ${ }^{1}$ Department of Public Health and Health Care Management, University of Applied Sciences Zwickau, Zwickau, \\ Germany \\ ${ }^{2}$ AOK PLUS, Department of Dental Services, Chemnitz, Germany \\ Email: ${ }^{*}$ carolinmaeding@gmx.de, Joerg.Klewer@fh-zwickau.de, robby.dietrich@plus.aok.de
}

Received 8 February 2015; accepted 26 February 2015; published 3 March 2015

Copyright (C) 2015 by authors and Scientific Research Publishing Inc.

This work is licensed under the Creative Commons Attribution International License (CC BY).

http://creativecommons.org/licenses/by/4.0/

(c) (i) Open Access

\begin{abstract}
Objective: The aim of the study was to analyze oral, dental and denture hygiene, and the current treatment needs in nursing home residents. Design: Cross-sectional design. Setting: Nursing homes in Saxony, Germany. Participants and Intervention: Participating dentists recorded the frequency of oral, dental and denture care, dental treatment needs, and the request for treatment in 11,144 nursing home residents by using standardized checklists. Results: Mean age of the residents was 82.5 years, and $\mathbf{7 4 . 6 \%}$ were females. For $54.0 \%$ of those examined, nursing staff did care for oral, dental, and denture hygiene. $77.5 \%$ of the residents performed oral hygiene more frequently than once daily, $19.8 \%$ only once a day, and $2.6 \%$ performed oral hygiene less frequent. A need for dental treatment was identified in $64.1 \%$ of the residents, of which $34.5 \%$ were missing dentures, and $29.7 \%$ suffered from dental diseases. $58.3 \%$ of the residents not requesting treatment had a clinical need for dental therapy. Objective and subjective need for treatment correlated positively $(p<0.001)$. Conclusion: Nursing home staff should be aware of the poor oral hygiene and health care conditions in residents. In addition to regular dental check-ups, nursing home residents should be given advice on dental care. Furthermore, dentists and health insurances should develop an action plan to improve oral health of nursing home residents, and to reduce additional costs due to lack of dental care.
\end{abstract}

\section{Keywords}

Oral Health Care, Nursing Home Residents, Request for Treatment, Dental Treatment Needs

\footnotetext{
${ }^{*}$ Corresponding author.
} 


\section{Introduction}

According to studies on oral health in nursing home residents, $22.8 \%$ of their teeth were carious, and $20.8 \%$ were destroyed completely [1]. In addition to very intensive plaque colonization on teeth and dentures, a furring of the tongue [1] and periodontal disease were most commonly diagnosed [2]. Impaired function of prostheses due to bad fitting under light pressure was found in $72 \%$ [3]. On average, the last contact to a dentist dated back three years (95\% CI: 2.3 to 4.1) [4]. The need for treatment is often perceived differently by the residents, thus a discrepancy between the quality of prostheses and the satisfaction of the participants was noted [3] [5].

The consequence of absent regular oral and dental care is the impairment of oral health such as pain, impairments in chewing and speaking [6].

Due to the lack of information on current dental needs among the nursing home residents in Saxony, Germany, their oral health conditions should be investigated. The study results should be used to develop recommendations to improve quality of oral health among nursing home residents.

\section{Methods}

The survey took part from July to December 2012. All nursing home residents insured by a statutory health insurance, which covers most of the nursing home residents, and their nursing homes in Saxony (Federal State in Germany) were informed. Voluntary participation and free choice of dentist care were emphasized. Anonymity of the participating nursing home residents was ensured, because blinding was not possible and would make no sense. Because of the non-invasive character of the survey with both no registration of personal data and no potential risk for the participants it was decided not to consult an ethical review board. Participation in the checkups did not result in an obligation for dental treatment. All dentists in Saxony working on base of a care contract with the statutory health insurers were informed about the potential participation in the study. Approximately 99\% of all dentists working in a private practice are working for statutory health insurances, which requires several years of professional experience. In order to increase the number of check-ups, all dentists participating by providing dental services and documenting the results, using a standardized checklists received an expense allowance for each resident included.

The standardized checklist included year of birth, gender, and level of nursing care, a classification system to classify need for nursing care in the German health insurance system $(0=$ no need for nursing care, only mental impairments; I = need for nursing care at least 90 minutes per day; II = need for nursing care at least 3 hours per day; III = intensive need for nursing care, at least 5 hours per day). The checklist also included need for dental treatment, information regarding the oral and denture care conditions, frequency of oral and dental care (once a day, more often, less often), and if dental hygiene was either performed alone by the resident or with the assistance by nurses. Furthermore, the need for dental treatment related to dental diseases, oral mucosal diseases, denture defects, missing dentures (objective need for treatment), the request for treatment (subjective need for treatment), and the option of treatment as well were documented. Statistical differences between groups were tested by using Pearson's chi-square test, the level of significance was set at $\alpha<0.05$.

\section{Results}

Altogether, 11,144 nursing home residents have been investigated, $74.6 \%$ of them were females, and mean age was 82.5 years. The level of nursing care was recorded in $95.2 \%$ of those examined: $45.3 \%$ were classified to nursing care level II (35.1\% care level I, 19.6\% care level III). In 54.0\% $(n=4995)$ of those examined oral care was performed by the nursing staff, of which most were classified into nursing care levels II and III $(n=4304)$ (Table 1). 3435 of the residents took care for their dental health without assistance, $69.0 \%(n=2134)$ of them were assigned to nursing care level I.

In $77.5 \%(n=8621)$ of the residents oral and denture care was performed more frequently than once daily, additional $19.8 \%(n=2205)$ performed oral care only once a day, and $2.6 \%(n=291)$ less frequent. Most of the investigated nursing home residents, who performed oral care more often than once a day, were assisted by nursing staff $(59.8 \%, \mathrm{n}=4197)$. In residents performing oral hygiene only once a day, $53.7 \%$ were assisted by nurses.

An objective need for treatment was diagnosed in $64.1 \%(n=7145)$ of the residents. Of these, approximately one-third had missing dentures and about $30 \%$ suffered from dental diseases. Approximately $40 \%$ of the resi- 
Table 1. Absolute and relative frequency in residents with and without oral, dental and denture care in relation to nursing care levels.

\begin{tabular}{cccccc}
\hline & \multicolumn{5}{c}{ Relative frequency of oral, dental and denture care [\%] } \\
\hline $\begin{array}{c}\text { Nursing } \\
\text { care level }\end{array}$ & $\begin{array}{c}\text { Absolute } \\
\text { frequencies N }\end{array}$ & $\begin{array}{c}\text { Alone } \\
(\mathbf{n}=\mathbf{3 4 3 5})\end{array}$ & $\begin{array}{c}\text { Assistance by } \\
\text { nurses (n= 4995) }\end{array}$ & $\begin{array}{c}\text { Alone and assistance } \\
\text { by nurses (n= 628) }\end{array}$ & $\begin{array}{c}\text { neither assistance by nurses } \\
\text { nor performed alone (n= 189) }\end{array}$ \\
\hline I & 3091 & 69.0 & 22.4 & 7.2 & 1.4 \\
II & 4224 & 28.5 & 60.8 & 8.6 & 2.0 \\
III & 1932 & 5.0 & 89.8 & 2.1 & 3.2 \\
Total & 9247 & 37.1 & 54.0 & 6.8 & 2.0 \\
\hline
\end{tabular}

dents below 65 years of age suffered from dental and oral mucosal diseases and 51.5\% had missing dentures (Table 2). Overall, 34.5\% of all age groups had missing dentures.

$73.7 \%$ of the residents requested dental treatment, of which $40.2 \%(n=3302)$ expressed the wish for future treatment. With an increasing nursing care level, the proportion of those who requested dental treatment dropped from $39.7 \%$ in care level I to $11.7 \%$ in care level III (29.1\% in care level II). In general, the proportion of male residents with a request for treatment was marginally higher in each care level than in female residents.

The need for dental treatment was indicated in $96.2 \%$ of the residents examined, but due to the health conditions, merely in $78.7 \%$ of them dental treatment has been classified as possible. Dental treatment was possible in most of the residents classified to nursing care level I (93.6\%) and II (80.7\%), but only in $45.8 \%$ of the residents classified to nursing care level III. In $98.6 \%(n=3228)$ of the residents requesting dental treatment, treatment was also indicated. Additional 45 residents expressed a wish for dental treatment, but, according to the dentists' opinion, the treatment was not possible. In $61.0 \%$ of the residents $(n=1632)$ who did not express a request for dental treatment, treatment would have been possible.

In $68.0 \%(n=2244)$ of the residents requesting treatment, (those with a subjective need for treatment) an objective need for treatment was also diagnosed (Table 3). 58.3\% $(n=2859)$, who did not request dental treatment presented need for dental treatment. A statistical correlation between objective and subjective need for dental treatment was found (Cramer's V $=0.109, \mathrm{p}<0.001$ ). Residents performing oral, dental and denture care more than once a day, $62.9 \%(n=5420)$ had an objective need for treatment, in those performing oral care only once a day, $66.8 \%(n=1472)$ had a need. An objective need for treatment was indicated for $81.8 \%(n=238)$ of residents who performed oral hygiene less than once daily. A statistical correlation was found between the frequency of oral, dental, and denture care and the objective need for treatment (Cramer's V $=0.068, \mathrm{p}<0.001$ ).

\section{Discussion}

The sample of residents investigated was representative in terms of gender and nursing care levels compared with the general population of nursing home residents in Saxony (cf. Saxon care statistics [7]). The extend of dental treatment before admittance to nursing home was not known, that is why being resident of a nursing home was not the factor influencing oral health.

However, general poor oral health conditions can be assumed, as in comparable studies [1]-[3]. The identified need for dental treatment in $58.3 \%$ of residents with no request for dental treatment confirms once again the discrepancy between objective needs for treatment and the subjective need for treatment [3] [5]. Likely lack of pain did lead to not requesting dental treatment [3]. As a need for treatment was identified in $68.0 \%$ of treatment requests, it would therefore be important to investigate subjective desires for dental treatment, which tend to display need for treatment.

Consequently the fact, that expressed satisfaction or refusal of dental treatment is not always accompanied by absence of symptoms and functionality of the denture, should be emphasized in training nursing staff of nursing homes, considering that a common reason for inadequate dental care was the lack of commitment in nursing home directors and nursing management [8] [9]. Due to the lack of awareness [9] and reduced knowledge in nurses regarding oral health and hygiene [1], the risk of complications such as tooth decay and tooth loss as well as limitations of functional chewing ability, and pronunciation can be minimized by means of dental training [1] [2]. Further measures to reach better oral health, like oral health education and practicing oral hygiene techniques, 
Table 2. Relative frequency of residents with dental treatment need related to age groups.

\begin{tabular}{ccccc}
\hline \multirow{2}{*}{ Age groups } & \multicolumn{4}{c}{ Relative frequency of dental treatment need [\%] } \\
\cline { 2 - 5 } & $\begin{array}{c}\text { Dental diseases } \\
(\mathbf{n}=\mathbf{3 2 6 0})\end{array}$ & $\begin{array}{c}\text { Oral mucosal diseases } \\
(\mathbf{n}=\mathbf{3 0 1 9})\end{array}$ & $\begin{array}{c}\text { Dentures defects } \\
(\mathbf{n}=\mathbf{2 6 7 0})\end{array}$ & $\begin{array}{c}\text { Missing dentures } \\
(\mathbf{n}=\mathbf{3 7 5 4})\end{array}$ \\
$\mathbf{5 6 4}$ & 40.9 & 40.6 & 13.6 & 51.5 \\
$\mathbf{6 5} \mathbf{- 6 9}$ & 40.7 & 37.0 & 21.0 & 42.0 \\
$\mathbf{7 0}-\mathbf{7 4}$ & 36.4 & 33.0 & 27.2 & 47.2 \\
$\mathbf{7 5}-\mathbf{7 9}$ & 37.4 & 31.6 & 26.6 & 40.4 \\
$\mathbf{8 0} \mathbf{- 8 4}$ & 30.8 & 28.6 & 28.1 & 33.4 \\
$\mathbf{8 5}-\mathbf{8 9}$ & 26.0 & 26.0 & 27.2 & 30.0 \\
$\mathbf{9 9 0}$ & 23.0 & 20.3 & 27.7 & 27.9 \\
\hline
\end{tabular}

Table 3. Absolute and relative frequency of residents with objective dental treatment need in relation to subjective dental treatment need.

\begin{tabular}{cccc}
\hline Request for dental treatment & Objective treatment need [\%] & No objective treatment need [\%] & Total N \\
\hline Yes & 68.0 & 32.0 & 3302 \\
No & 58.3 & 41.7 & 4908 \\
No statement & 69.6 & 30.4 & 2934 \\
Total & 64.1 & 35.9 & 11,144 \\
\hline
\end{tabular}

would help to meet subjective and objective conditions, because individual advises regarding oral hygiene lead to improved oral hygiene in nursing home residents [10].

Dental examinations should be offered in addition to medical examinations when a person moves into a nursing home. Dental visits should take place at least annually, including individual advices about treatment options. Unfavorable working conditions of dentists in nursing homes are another likely reason to explain the lack of dental services [11]. Mobile treatment units could therefore be beneficial in allowing examinations on a chair or on the bed of the resident. The costs of dental visits to nursing homes should be compared to the costs of nursing staff and transport incurred on the way to the dentist's surgery. Due to the uncertainties in treatment decisions further training in gerontostomatology could be productive [11].

The high percentage of residents with need for dental care raises the question, why they did not get dental care before, which is covered by the statutory health insurance in Germany. Need for dental care was now first covered after paying an additional expense fee to the dentists. Maybe dentists' expenses for nursing home visits are still not covering all costs [11]. This criticism was taken into account by implementing an additional benefit in paying for dental services by statutory health insurances in 2013 [12]. By this, improved oral health in nursing home residents should be achieved in the near future. Nursing homes should be also encouraged to cooperate with dentists on an official base [12].

\section{Conclusion}

To improve the oral health of nursing home residents and reduce treatment costs due to lack of dental care and costs associated with secondary diseases as well, cooperation between dentists, nursing homes, and statutory health insurances are recommended. They should create action plans to improve dental care among nursing home residents, leading to better oral health and quality of life.

\section{Conflict of Interest}

The authors do declare no conflict of interest. 


\section{References}

[1] Jäger, S., Köster-Schmidt, A., Schade, M. and Heudorf, U. (2009) Oral Hygiene in Nursing Home Residents. Impact of an Oral Health Education Programme for the Nursing Personnel on the Residents' Oral Health [Original in German]. Bundesgesundheitsblatt-Gesundheitsforschung-Gesundheitsschutz, 52, 927-935. http://dx.doi.org/10.1007/s00103-009-0940-3

[2] Czarkowski, G., Allroggen, S., Köster-Schmidt, A., Bausback-Schomakers, S., Frank, M. and Heudorf, U. (2013) Oral Health Hygiene Education Programme for Nursing Personnel to Improve Oral Health of Residents in Long-Term Care Facilities 2010 in Frankfurt/Main, Germany [Original in German]. Gesundheitswesen, 75, 368-375.

[3] Coca, I. and Vidac, A.A. (2006) Oral Status and Subjective Estimation of Dental Protheses by Inhabitants of Old People’s Homes [Original in German]. Das deutsche Zahnärzteblatt, 115, 362-367. http://dx.doi.org/10.1055/s-2006-954595

[4] Hassel, A.J., Koke, U., Schmitter, M. and Rammelsberg, P. (2006) Factors Associated with Oral Health-Related Quality of Life in Institutionalized Elderly. Acta Odontologica Scandinavica, 64, 9-15. http://dx.doi.org/10.1080/00016350500326211

[5] Knabe, C. and Kram, P. (1997) Dental Care for Institutionalized Geriatric Patients in Germany. Journal of Oral Rehabilitation, 24, 909-912. http://dx.doi.org/10.1046/j.1365-2842.1997.00196.x

[6] Kassenzahnärztliche Bundesvereinigung (KZBV), and Bundeszahnärztekammer (BZÄK) (2010) Oral Health Despite Handicap and Old Age [Original in German]. Kassenzahnärztliche Bundesvereinigung (KZBV), and Bundeszahnärztekammer (BZÄK), Berlin.

[7] Statistical Office of Saxony (2013) Long-Term Care Insurance in Saxony. Nursing Care Facilities, Nursing Staff and People in Need of Care 2001. Staatsbetrieb Sächsische Informatik Dienste.

[8] Nitschke, I., Vogl, B., Töpfer, J. and Reiber, T. (2000) Oral Health Status of Seniors in Nursing Homes in East Germany [Original in German]. Deutsche Zahnärztliche Zeitschrift, 55, 707-713.

[9] Nitschke, I., Majdani, M., Sabotta, B.A.J., Reiber, T. and Hopfenmüller, W. (2010) Dental Care of Frail Older People and Those Caring for Them. Journal of Clinical Nursing, 19, 1882-1890. http://dx.doi.org/10.1111/j.1365-2702.2009.02996.x

[10] Zenthöfer, A., Dieke, A., Wege, K.C., Rammelsberg, P. and Hassel, A.J. (2013) Improving Oral Hygiene in the Long-Term Care of the Elderly-A RCT. Community Dentistry and Oral Epidemiology, 41, 261-268. http://dx.doi.org/10.1111/cdoe.12007

[11] Nitschke, I., Ilgner, A. and Müller, F. (2005) Barriers to Provision of Dental Care in Long-Term Care Facilities: The Confrontation with Ageing and Death. Gerodontology, 22, 123-129. http://dx.doi.org/10.1111/j.1741-2358.2005.00078.x

[12] Social Care Act V, Statutory Health Insurance (1988) German Federal Law Gazette I, 2477. (Last Amended by Article 5 of the Act of 23 December 2014 (German Federal Law Gazette I p. 2462)). 